(2) Open Access Full Text Article

\title{
Development and characterization of gastroretentive sustained-release formulation by combination of swelling and mucoadhesive approach: a mechanistic study
}

This article was published in the following Dove Press journal:

Drug Design, Development and Therapy

4 December 2013

Number of times this article has been viewed

\author{
R Sankar' \\ Subheet Kumar Jain ${ }^{1,2}$ \\ 'Department of Pharmaceutical \\ Sciences and Drug Research, Punjabi \\ University, Patiala, Punjab, India; \\ ${ }^{2}$ Department of Pharmaceutical \\ Sciences, Guru Nanak Dev \\ University, Amritsar, Punjab, India
}

Correspondence: Subheet Kumar Jain Department of Pharmaceutical Sciences, Guru Nanak Dev University, Amritsar, Punjab, 143 005, India

Tel $+91 \quad 1832258802$

$\mathrm{Fax}+91 \quad 1832258819$

Email subheetjain@gmail.com
Background: Acyclovir has pharmacokinetic limitations, including poor oral bioavailability of $15 \%-30 \%$, high variability, and short elimination half-life of 2.3 hours. These limitations necessitate frequent administration of acyclovir, up to five times daily, leading to poor patient compliance, which in turn leads to a reduction in therapeutic efficacy and development of resistance.

Methods: A gastroretentive sustained-release (GR) formulation of acyclovir, based on a combination of swelling and mucoadhesive mechanisms, has been developed. Composition has been optimized after evaluation of different polymers, carbomer, polyethylene oxide, and sodium alginate alone and/or in combination. GR formulations were characterized for in-process quality-control tests, drug release and release rate kinetics, similarity factor analysis, swelling index, and matrix erosion.

Results: A formulation containing a combination of carbomer and polyethylene oxide had the highest similarity of drug release compared with a target drug-release profile obtained by pharmacokinetic simulations. The measurement of mucoadhesive strength, carried out with a texture analyzer, showed that the mucoadhesive strength of the GR formulation was significantly higher than that of the immediate-release (IR) tablet. The optimized GR formulation was found to be retained in the upper part of the gastrointestinal tract for 480 minutes; the IR tablet was retained for only 90 minutes as measured using a gastrointestinal retention study in albino rabbits. The GR formulation was also found to maintain more sustained plasma concentrations than the IR tablet. Mean residence time of the GR formulation was 7 hours versus 3.3 hours for the IR formulation. The relative bioavailability of the GR formulation was $261 \%$ of the IR formulation.

Conclusion: The GR formulation of acyclovir, based on swelling and mucoadhesive mechanisms, has prolonged retention in the upper gastrointestinal tract, sustained in vitro drug release, prolonged in vivo absorption, and better bioavailability than the IR formulation. Such a formulation would improve patient compliance and increase the efficacy of therapy.

Keywords: gastroretentive, swelling and mucoadhesive mechanism, mucoadhesive measurement, GI retention study, pharmacokinetic study

\section{Introduction}

Oral sustained-release (SR) dosage forms have retained prominence for the past 3 decades due to their clinical advantages in comparison with their immediate-release (IR) forms. ${ }^{1}$ However, the conventional SR formulations are not suitable for drugs possessing a narrow absorption window in the upper part of the gastrointestinal tract (GIT). 
These formulations are rapidly cleared from the upper GIT, resulting in the release of a significant fraction of the drug in non-absorbing distal segments of the GIT. This leads to a short absorption phase and poor bioavailability of the drug. ${ }^{2}$ Many drugs, such as ciprofloxacin, ofloxacin, levodopa, iron, and acyclovir, are preferentially absorbed from the upper GIT. It has been reported that, when drugs with a narrow absorption window are formulated as gastroretentive SR (GR) formulations, they have higher bioavailability due to an extended absorption phase. ${ }^{3}$ The ciprofloxacin once-daily tablet and ofloxacin once daily are the well-known commercially available GR formulations. After oral administration, GR formulations are retained within the stomach and therein release the drug in a controlled manner, so the drug is supplied continuously to its absorption sites in the upper GIT. This would be the best mode of administration for these drugs to achieve the pharmacokinetic and pharmacodynamic advantages of SR dosage forms. ${ }^{4}$

In our previous study, we prepared, optimized, and characterized mucoadhesive microspheres of acyclovir. ${ }^{5}$ We found a significant increase in bioavailability and mean residence time (MRT) when acyclovir was administered as mucoadhesive microspheres in comparison with the plain drug. The simplicity and scalability of the manufacturing process is important for the preparation of any formulation at the commercial level. Methods employed in the manufacture of microsphere-based GR formulations suffer significant shortfalls and limitations (eg, the multistep process, use of organic solvents that must be removed from the final formulation, requirement for high shear conditions, and a lengthy post-processing time period) that potentially hinder commercial success. The preparation of SR tablets is well established at the commercial level due to the use of technology similar to that used to manufacture IR tablets. In the present study, we attempted to prepare, optimize, and characterize GR tablet formulations of acyclovir using a combination of swelling and mucoadhesion mechanisms. GR dosage forms using various approaches, such as high-density systems, ${ }^{6}$ floating systems, ${ }^{7}$ expandable systems, ${ }^{8,9}$ superporous hydrogels, ${ }^{10}$ mucoadhesive/bioadhesive systems, ${ }^{11}$ and magnetic systems, ${ }^{12}$ have been reported in the literature. In the present study, a combination of mucoadhesion and swelling was used. While bioadhesion ensures adhesion of the dosage form onto gastric mucosa, rapid and high degrees of swelling help to delay clearance through the pyloric sphincter.

Acyclovir has pharmacokinetic limitations, such as poor oral bioavailability $(15 \%-30 \%)$, high variability, and a short elimination half-life of 2.3 hours. ${ }^{13,14}$ These limitations necessitate the frequent administration of acyclovir, up to five times daily, leading to poor patient compliance, which in turn leads to a reduction in therapeutic efficacy and development of resistance. Acyclovir is soluble in acidic $\mathrm{pH}$ and is predominantly absorbed from the upper GIT. There are indications that the drug is absorbed only from the upper GIT. ${ }^{15}$ In commercially available IR dosage forms, the fraction of dose absorbed is very low due to the short residence time of the dosage form at the absorption site. As a result, most of the drug is excreted in the feces $(50 \%-60 \%)$, in an unabsorbed form. ${ }^{16}$

The aim of the present study was to prepare and optimize a GR tablet formulation based on swelling and mucoadhesive mechanisms. Although some studies have already been conducted on GR tablet dosage forms of acyclovir, ${ }^{17,18}$ this study is the first to formulate a GR dosage form based on target dose and an in vitro drug-release profile obtained through pharmacokinetic simulations. ${ }^{19}$ An attempt was also made to evaluate the mechanism of gastroretention by studying the swelling and matrix erosion kinetics and by quantitative evaluation of bioadhesion using a texture analyzer. In vivo radiographic and pharmacokinetic studies were performed in rabbits to evaluate gastroretention and associated pharmacokinetic advantages over conventional dosage forms.

\section{Materials and methods Materials}

Acyclovir was obtained as a gift sample from Ranbaxy Laboratories Limited (Gurgaon, India). Carbomer (Carbopol 974P) was a gift sample from Lubrizol Advanced Materials India Private Limited (Mumbai, India). Polyethylene oxide (Polyox WSR 303) was purchased from Colorcon Asia Private Limited (Goa, India). Sodium alginate (Keltone ${ }^{\circledR}$ HVCR) and microcrystalline cellulose (Avicel PH 101) were received as gift samples from Signet Chemical Corporation Private Limited (Mumbai, India). Povidone K 30 (Plasdone K 29/32) was purchased from International Specialty Products (Hyderabad, India). Colloidal silicon dioxide (Aerosil 200) was purchased from Evonik Industries (Mumbai, India). Magnesium stearate (Hyqual ${ }^{\circledR}$, vegetable source) was purchased from Mallinckrodt Baker India (Mumbai, India). Isopropyl alcohol was purchased from Avantor Performance Materials India Limited (Faridabad, India). Barium sulfate was procured from Merck (Mumbai, India).

\section{Characterization of acyclovir Angle of repose}

Acyclovir was passed through a funnel kept at a height of $3 \mathrm{~cm}$ from the base. The powder was passed until it formed a 
heap and touched the tip of the funnel. The radius of the base of the conical pile and the height of the pile were measured, and the angle of repose was calculated using Equation 1,

$$
\theta=\tan ^{-1}(\mathrm{~h} / \mathrm{r})
$$

where $\theta$ is the angle of repose, $h$ is the height of the pile, and $r$ is the radius of the base of the pile.

\section{Bulk density and tapped density}

The weighed quantity of acyclovir (electronic weighing balance: GP 8201, Sartorius AG, Germany) was transferred into a $100 \mathrm{~mL}$ measuring cylinder without significant mechanical stresses during transfer. The volume occupied by the drug was measured initially and after subjecting to 1,250 taps in a tap density tester (ETD1020, Electrolab, Mumbai, India). Bulk and tapped density were calculated using Equations 2 and 3, respectively,

$$
\begin{gathered}
\operatorname{Bulkdensity}\left(\rho_{\mathrm{i}}\right)=\frac{\mathrm{m}}{\mathrm{v}_{\mathrm{i}}}, \\
\operatorname{Tapped} \operatorname{density}\left(\rho_{\mathrm{t}}\right)=\frac{\mathrm{m}}{\mathrm{v}_{\mathrm{t}}},
\end{gathered}
$$

where $\mathrm{m}$ is the mass of the $\operatorname{drug}(\mathrm{g}), \mathrm{v}_{\mathrm{i}}$ is the initial volume $(\mathrm{mL})$, and $\mathrm{v}_{\mathrm{t}}$ is the tapped volume $(\mathrm{mL})$.

\section{Compressibility index}

The compressibility index (CI) was expressed as a percentage and calculated using Equation 4 or 5,

$$
\begin{aligned}
& C I=\frac{\rho_{t}-\rho_{i}}{T D} \times 100, \\
& C I=\left(\frac{v_{i}-v_{t}}{v_{i}}\right) \times 100 .
\end{aligned}
$$

\section{Hausner's ratio}

Hausner's ratio was determined by the ratio of tapped density and bulk density based on Equation 6,

$$
\text { Hausner's ratio }=\left(\frac{\mathrm{v}_{\mathrm{i}}}{\mathrm{v}_{\mathrm{t}}}\right) \text { or } \frac{\mathrm{TD}}{\mathrm{BD}} \text {. }
$$

\section{Drug-excipient compatibility study}

The suitability of excipients with respect to their influence on the stability of acyclovir was evaluated through drug-excipient compatibility studies. Mixtures of acyclovir with individual excipients were prepared, and these mixtures were packed in glass vials (type I) as well as low-density polyethylene (LDPE) bags. These samples were stored in stability chambers (NEC2355; Newtronic, Mumbai, India). Samples packed in glass vials were stored at $60^{\circ} \mathrm{C}$ and $40^{\circ} \mathrm{C}, 75 \%$ relative humidity (RH), and those packed in LDPE bags were stored in $40^{\circ} \mathrm{C}$, $75 \%$ RH. Samples were withdrawn after predefined time intervals and analyzed for guanine content, the major impurity of acyclovir, using high-performance liquid chromatography (HPLC). ${ }^{20}$ Samples were also observed for physical/morphological changes in terms of color or lump formation.

\section{Preparation of GR tablets}

Compositions of various batches of acyclovir GR formulations are summarized in Table 1. Hydrophilic, mucoadhesive, polymer matrix tablets were prepared via the wet granulation method. Acyclovir, polymer(s), and microcrystalline cellulose were weighed (electronic weighing balance: AG204; Mettler-Toledo International Inc, Columbus, OH, USA/GP8201; Sartorius AG, Gottingen, Germany) and sifted together through a \#40 ASTM sieve and blended in a polybag for 5 minutes. This blend was then granulated manually using a binder solution prepared by dissolving povidone K 30 in isopropyl alcohol. The wet mass was dried in a tray dryer for 60 minutes at $50^{\circ} \mathrm{C}$ to obtain loss on drying of $<2 \% \mathrm{w} / \mathrm{w}$ (IR moisture analyzer-MA 100, Sartorius AG, Germany). The dried mass was passed through a \#20 ASTM sieve to form granules. The resultant granules were lubricated by blending with magnesium stearate (previously sifted through a \#60 ASTM sieve) in a polybag. This lubricated blend was compressed manually (tablet press model CMD3-16, Cadmach, India) using a $19 \mathrm{~mm} \times 9 \mathrm{~mm}$, modified capsule-shaped, concave, plain punch with beveled edges.

\section{In-process characterization}

Properties of the acyclovir GR tablets, such as hardness, friability, thickness, and weight variation, were determined as in-process characterization. Hardness was determined by using a tablet hardness tester (VK200, Varian Inc, Cary, NC, USA). Friability was determined using Roche friability testing apparatus (EF-1W, Electrolab, Mumbai, India) as per procedures described in the Indian Pharmacopoeia (IP). ${ }^{21}$ Weight variation was also performed according to the IP procedure. ${ }^{22}$ Thickness of tablets was determined using a digital vernier caliper (Mitutoyo Corporation, Kawasaki, Japan). 


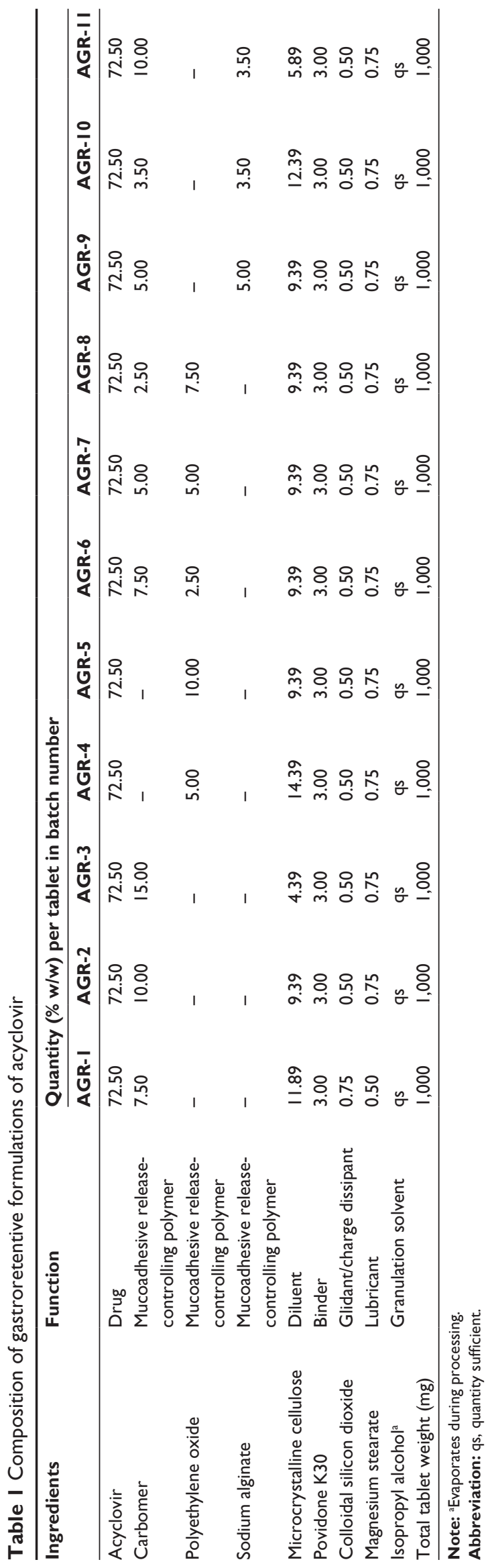

\section{In vitro drug-release studies}

In vitro drug-release studies were performed using USP type II dissolution apparatus (paddle) at $50 \mathrm{rpm}$ (VK7010 with VK8000 Auto sampler, Varian Inc). The drug-release medium was $900 \mathrm{~mL}$ of $0.1 \mathrm{~N} \mathrm{HCl}$ at a temperature of $37^{\circ} \mathrm{C} \pm 0.5^{\circ} \mathrm{C}$. An aliquot $(10 \mathrm{~mL})$ was withdrawn at specific time intervals (1, 2, 4, 6, 8, 10, and 12 hours), and drug content was determined by ultraviolet-visible spectrophotometer (Cary 50 , Varian Inc) at $255 \mathrm{~nm}$. Immediately after withdrawal of the sample, $10 \mathrm{~mL}$ of $0.1 \mathrm{~N} \mathrm{HCl}$ maintained at $37^{\circ} \mathrm{C} \pm 0.5^{\circ} \mathrm{C}$ was replaced to maintain the volume of dissolution medium constant. We ensured that none of the ingredients used in the tablet formulations interfered with the analysis. When the formulations were subjected to in vitro drug-release studies, their swelling behavior and other physical changes were also observed.

\section{Similarity factor analysis}

Similarity factor $\left(\mathrm{f}_{2}\right)$ is a simple and model-independent approach to comparing drug-release profiles. ${ }^{23}$ It is a logarithmic reciprocal square root transformation of the sum of the squared error and is a measurement of the similarity in the percent dissolution (drug release) between the two curves. Two drug-release curves are said to be similar if $\mathrm{f}_{2}$ is between 50 and 100; $\mathrm{f}_{2}$ was determined using Equation 7,

$$
\mathrm{f}_{2}=50 \cdot \log \left\{\left[1+(1 / \mathrm{n}) \sum_{\mathrm{t}=1}^{\mathrm{n}}\left(\mathrm{R}_{\mathrm{t}}-\mathrm{T}_{\mathrm{t}}\right)^{2}\right]^{-0.5} \cdot 100\right\},
$$

where $R_{t}$ is the percentage drug release of reference at time $t$, and $T_{t}$ is the percentage drug release of test at time $t$.

We determined $\mathrm{f}_{2}$ for all formulations. The target drugrelease profile obtained in pharmacokinetic simulations was used as a reference, and respective drug-release profiles of different batches of GR tablets were used as a test.

\section{Release kinetics}

Drug-release data of selected batches were fitted into zeroorder, first-order, Higuchi, Korsmeyer-Peppas, and HixsonCrowell equations. ${ }^{24}$ To study the mechanism of drug release, the well-known exponential equation (Korsmeyer equation), often used to describe drug-release behavior from polymeric systems, was used. ${ }^{25}$

$$
\log \left(\mathrm{M}_{\mathrm{t}} / \mathrm{M}_{\mathrm{f}}\right)=\log \mathrm{k}+\mathrm{n} \log \mathrm{t}
$$

where $M_{t}$ is the amount of drug released at time $t ; M_{f}$ is the amount of drug released after infinite time; $\mathrm{k}$ is a release 
rate constant, incorporating structural and geometric characteristics of the tablet; and $\mathrm{n}$ is the diffusional exponent indicative of the mechanism of drug release. The $n$ value is obtained from the regression line of a plot of $\log \%$ drug released versus log time. A value of $n=0.45$ indicates Fickian (case I) release; $>0.45$ but $<0.89$ for anomalous (non-Fickian) diffusion, indicating a combination of diffusion and erosion-controlled drug release; and 0.89 or above indicates super case II type of release, referring to erosion of the polymeric chain.

\section{Swelling index and matrix erosion}

Swelling index and matrix erosion studies were performed by a method similar to that reported by Al-Taani and Tashtoush, ${ }^{26}$ using USP type II dissolution test apparatus (VK7010 with VK8000 Auto sampler, Varian Inc). The tablets were accurately weighed and dropped into the dissolution vessel containing $900 \mathrm{~mL}$ of $0.1 \mathrm{~N} \mathrm{HCl}(\mathrm{pH} \mathrm{1.2)} \mathrm{maintained}$ at $37^{\circ} \mathrm{C} \pm 0.5^{\circ} \mathrm{C}$; speed of rotation was $50 \mathrm{rpm}(\mathrm{n}=3)$. At $0.25,0.5,0.75,1,1.5,2,2.5,4,6$, and 8 hours, the residual matrix was carefully removed from the dissolution vessel and weighed. The residual matrix was then dried in a hot air oven at $60^{\circ} \mathrm{C}$ for 12 hours and reweighed. The percentage swelling index (ie, the degree of swelling due to absorbed medium) was calculated using Equation 9,

$\%$ swelling index $=\frac{\text { Weight of swollen tablet }}{\text { Weight of eroded tablet }} \times 100$.

(after drying)

Percentage erosion was calculated from Equation 10,

$$
\% \text { erosion }=\frac{\begin{array}{l}
\text { Initial weight of the tablet }- \text { weight } \\
\text { of eroded tablet }(\text { after drying })
\end{array}}{\text { Initial weight of the tablet }} \times 100 \text {. }
$$

\section{Measurement of mucoadhesive strength}

The mucoadhesive strength of acyclovir GR tablets on goat gastric mucosa was determined using a texture analyzer (TA.XT.Plus, Stable Microsystems Ltd, Godalming, UK). A commercially available IR formulation, Zovirax ${ }^{\circledR}$ (GlaxoSmithKline, Mumbai, India), was used for comparison purposes. Use of goat gastric mucosa has been widely reported for evaluation of mucoadhesive strength of mucoadhesive formulations ${ }^{27,28}$ and it is easily available. Immediately after slaughter, the stomach of the goat was removed and cleaned using ice-cold Krebs ringer solution ( $\mathrm{pH}$ 6.8). This solution contained $115 \mathrm{mM}$ sodium chloride; $5.9 \mathrm{mM}$ potassium chloride; $1.2 \mathrm{mM}$ each of magnesium chloride, sodium dihydrogen phosphate, and sodium sulfate; $2.5 \mathrm{mM}$ calcium chloride; $25 \mathrm{mM}$ sodium bicarbonate; and $10 \mathrm{mM}$ glucose per liter of solution.

A piece of gastric mucosa measuring about $2 \mathrm{~cm} \times 2 \mathrm{~cm}$ was mounted securely in the tissue holder of the texture analyzer, with mucosa facing upwards. The tablet was fixed to the probe with double-sided adhesive tape. The surface of the tablet was immersed in $0.1 \mathrm{~N} \mathrm{HCl}$ for 30 seconds and then allowed to equilibrate for 90 seconds. The probe was lowered at a speed of $0.5 \mathrm{~mm} / \mathrm{second}$ and allowed to be in contact with the mucosa with a force of $10 \mathrm{~g}$ for 300 seconds. The probe was then withdrawn at a speed of $0.5 \mathrm{~mm} / \mathrm{second}$ with a trigger force of $5 \mathrm{~g}$. The force required to detach the formulation from the tissue surface was determined as the peak value in resultant force-time plot. This experiment was carried out in triplicate and a fresh piece of gastric mucosa was used in each replicate. Three formulations containing a combination of carbomer and polyethylene oxide were included in this experiment (AGR-6, AGR-7, and AGR-8).

\section{Gastroretention study}

The gastroretention study was conducted on albino rabbits and was based on X-ray radiography. Albino rabbits were chosen as the experimental animals as previously reported in the literature for evaluation of gastroretention and bioavailability of gastroretentive formulations. ${ }^{27,29-31}$ The study was conducted on six healthy rabbits weighing $1.8 \mathrm{~kg}-2.4 \mathrm{~kg}$. Animals were grouped into two groups of three animals each. A small $(6.0 \mathrm{~mm})$ conventional tablet formulation and the optimized small GR tablet $(6.0 \mathrm{~mm})$ were administered, along with water, to the first and second groups, respectively. Both the formulations contained $72.5 \mathrm{mg}$ of acyclovir per tablet. The optimized GR tablet contained a combination of AGR-7, ie, carbomer and polyethylene oxide $(75: 25)$. To make the tablet X-ray opaque, barium sulfate in $10 \% \mathrm{w} / \mathrm{w}$ concentration was included. The small tablets were also characterized for shape, size, thickness, hardness, friability, drug content, and in vitro drug release. The $\mathrm{f}_{2}$ of the drug-release profile of small tablets is more than 50 when compared with AGR-6. During the study, the animals were not allowed to eat, but water was available ad libitum. $\mathrm{X}$-ray photography of the abdominal region was taken at 0,1 , $1.5,2,4,6,8$, and 12 hours after administration of the tablets. ${ }^{32}$ All animal investigations were performed after approval by the Institutional Animal Ethics Committee of the Department of Pharmaceutical Sciences and Drug Research, Punjabi University, Patiala, India, and in accordance with the disciplinary principles and guidelines of the Committee for the Purpose of 
Control and Supervision of Experiments on Animals, Ministry of Environment and Forests, Government of India.

\section{Pharmacokinetic study}

Protocols similar to those used for the gastrointestinal retention study were used for the pharmacokinetic study. At 0 , $0.5,0.75,1,1.5,2,4,5,6,8,10,12,14,18$, and 24 hours, blood was collected from the ear vein in tubes coated with anti-coagulant, and centrifuged at 4,000 rpm for 10 minutes (Remi equipment, Mumbai, India). Acetonitrile was added to the supernatant to precipitate the proteins. The precipitated proteins were settled by centrifugation at 4,000 rpm for 15 minutes. The supernatant was filtered through a $0.45 \mu \mathrm{m}$ filter, and the drug concentration was determined via the HPLC method. ${ }^{33}$ A mixture of glacial acetic acid in water was used as the mobile phase. The injected fluid $(20 \mu \mathrm{L})$ was eluted in C-18 column $4.6 \mathrm{~mm} \times 250 \mathrm{~mm}$, HyperSil, at room temperature, and acyclovir content was analyzed at $254 \mathrm{~nm}$ using a diode array ultraviolet detector (1260 Series, Agilent, Santa Clara, CA, USA). Pharmacokinetic parameters were calculated using non-compartmental analysis (WinNonlin 5.1.3, Certara, LP, St Louis, MO, USA).

\section{Stability study}

A stability study of the optimized formulation was conducted at accelerated stability test conditions as per International
Conference on Harmonisation (ICH) guidelines. ${ }^{34}$ Since the storage conditions of the accelerated test condition are harsher than intermediate- or long-term conditions, the former was used to evaluate the stability of the formulation within a shorter time period. Tablets were packed in aluminum blisters and stored at $40^{\circ} \mathrm{C}, 75 \% \mathrm{RH}$, in a stability chamber (NEC2355, Newtronic, India). Samples were withdrawn after 1, 2, and 3 months, and tested for assay, water content, guanine content, and drug release.

\section{Results and discussion \\ Preparation and characterization of GR formulations}

The strength of the acyclovir (725 mg) and target drug-release profiles were determined via pharmacokinetic simulations. Simulations were carried out using reported pharmacokinetic parameters of IR tablets of acyclovir. ${ }^{14}$ Detailed methodology used for the simulations has been described in our previous publication. ${ }^{19}$ Figure 1 shows the simulated steady-state plasma concentration profiles of the $200 \mathrm{mg}$ IR formulation (administered five times daily) and the $723 \mathrm{mg}$ SR formulation (administered two times daily), along with the target in vitro drug-release profile for the SR formulation.

Carbomer, polyethylene oxide, and sodium alginate were used as mucoadhesive release-controlling polymers,

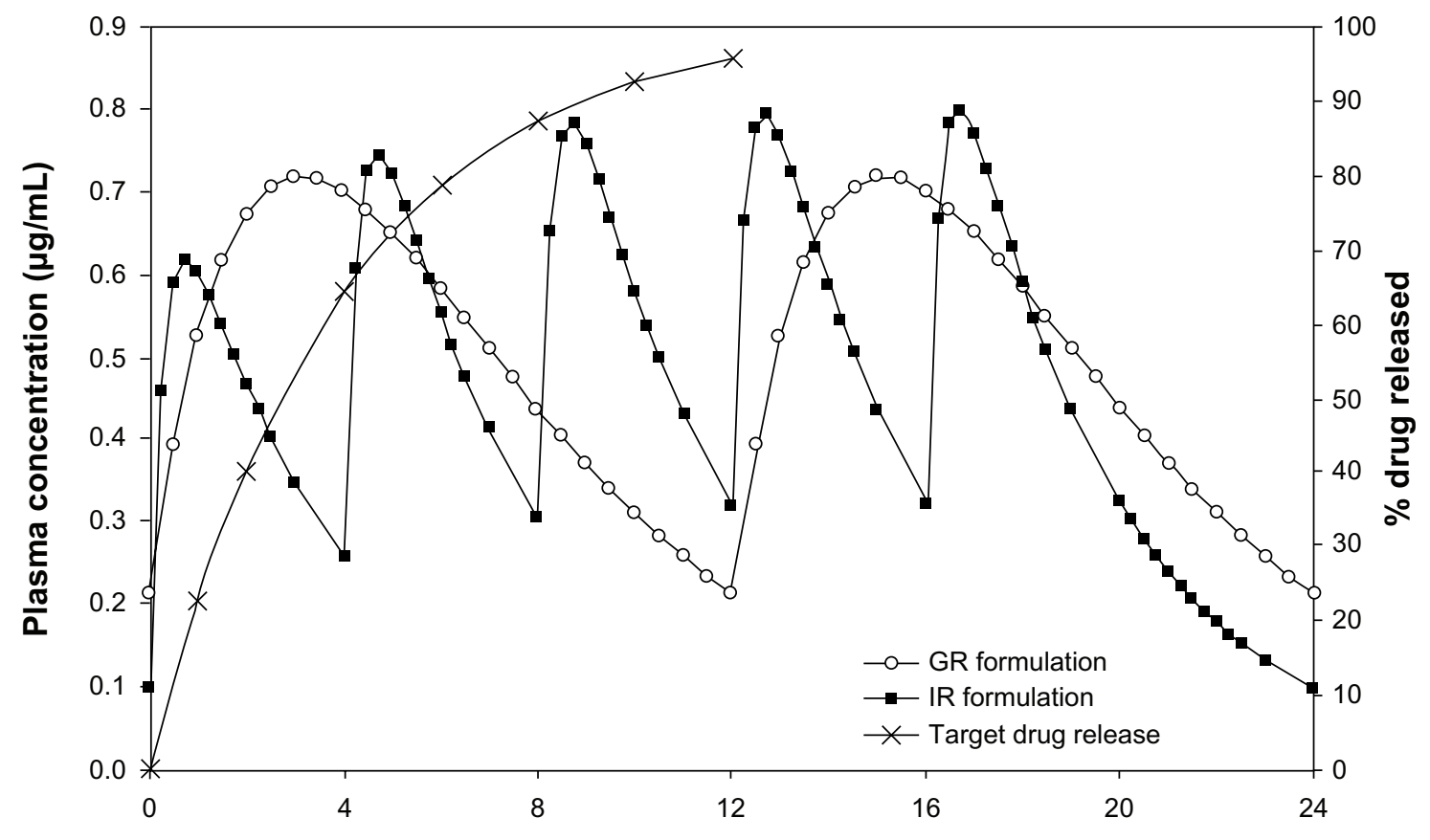

Time (h)

Figure I Comparison of simulated steady state plasma concentration profiles of the IR and GR formulations of acyclovir along with target drug release profile. Abbreviations: GR, gastroretentive sustained-release; IR, immediate-release; $h$, hours. 
either individually or in combination. These polymers have good gel-forming abilities and high degrees of swelling, ${ }^{35-37}$ which will assist with retention of tablets in the stomach, without allowing them to pass through the pyloric sphincter. Moreover, their chemical structures allow them to form numerous hydrogen bonds, which is crucial for strong mucoadhesion..$^{38-40}$ They are widely used in drug products and cosmetics as release-controlling polymers and viscosity modifiers.

Table 2 shows the results of the drug-excipient compatibility study. All excipients used in the formulation of acyclovir GR tablets were included in this study. Compatibility of a drug with excipients is an important criterion when including a particular excipient in a formulation. It is predictive of possible stability failures of the drug product, particularly regarding impurities. There was no significant increase in impurity levels (guanine) with all excipients at $60^{\circ} \mathrm{C}$ in glass vials. In the case of the drug-carbomer mixture, there was a significant increase in impurity at $40^{\circ} \mathrm{C}, 75 \% \mathrm{RH}$, in samples packed in LDPE bags, but a similar increase was not observed in samples packed in glass vials. Since the samples packed in glass vials are completely protected from moisture, but those packed in LDPE bags are not, it can be concluded that the increase in impurities in LDPE bags is due to the absorption of moisture. This conclusion was also supported by soft lumps observed at $40^{\circ} \mathrm{C}, 75 \% \mathrm{RH}$, in the drug-carbomer mixture packed in LDPE bags. Hence, carbomer was not excluded from the formulation, as the final formulation can be protected from moisture by packaging in aluminum blister packs, which are completely impermeable to moisture. We observed no other chemical incompatibilities in our studies. Shahi et $\mathrm{al}^{41}$ have also reported that there was no drug-excipient interaction between acyclovir and polyethylene oxide or povidone using differential scanning calorimetry (DSC) and Fourier transform infrared spectroscopy (FTIR) studies. Neither the impurity levels nor the physical appearance of mixtures with other excipients changed in any packs and conditions.

Results of various characterization tests performed on acyclovir are shown in Table 3. Acyclovir possesses an angle of repose value of greater than $40^{\circ}$, indicating a very poor flow property. The compressibility of acyclovir is also extremely poor, as the CI was found to be $39.47 \%{ }^{42}$

Due to the poor flow properties of acyclovir, we selected a granulation process to prepare GR tablets. As the calculated dose of acyclovir was high $(725 \mathrm{mg})$, the quantity of excipients has to be less, to avoid increasing the size of the tablet, which would be very difficult to swallow. Hence, a wet

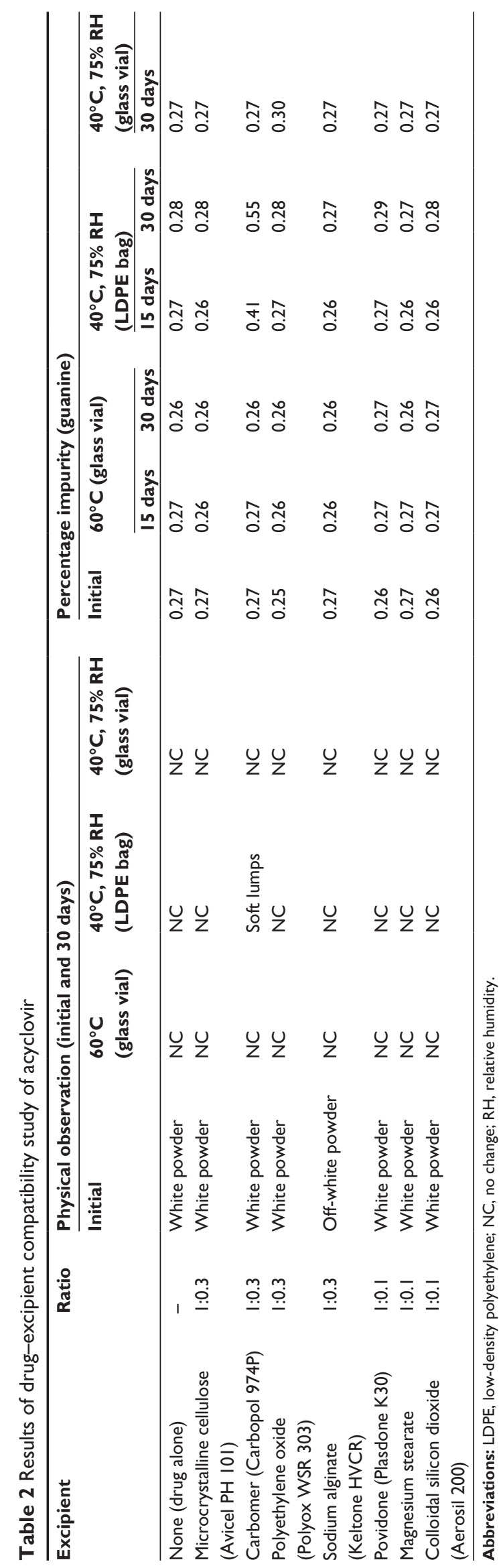


Table 3 Characterization of acyclovir

\begin{tabular}{lll}
\hline Serial number & Parameter & ACV powder \\
\hline $\mathrm{I}$ & Angle of repose $^{\mathrm{a}}$ & $41.6^{\circ} \pm 0.3^{\circ}$ \\
2 & Bulk density & $0.58 \mathrm{~g} / \mathrm{mL}$ \\
3 & Tapped density & $0.96 \mathrm{~g} / \mathrm{mL}$ \\
4 & Compressibility index & $39.74 \%$ \\
5 & Hausner's ratio & 1.65 \\
\hline
\end{tabular}

Note: aData represented as mean \pm SD $(n=3)$.

Abbreviations: ACV, acyclovir; SD, standard deviation.

granulation process was selected, which provides intimate contact between the drug and polymer and better control of drug release at low concentrations of polymer. All the polymers used in the preparation were hydrophilic and swollen in the presence of water. This property makes the drying process of the wet mass after granulation very difficult, if water is used as a granulating solvent. Therefore, wet granulation was performed using isopropyl alcohol as the solvent. Isopropyl alcohol is a widely used granulating solvent in the pharmaceutical industry. It is a very safe solvent to use in oral dosage forms, and has been classified as a solvent with low toxic potential by ICH. ${ }^{43}$

Table 4 shows the results of in-process characterization of GR formulations. GR tablets of acyclovir were very compact. Their surface was very smooth and shiny. The weight variation and friability were found to comply with official limits. Tablets were of high mechanical strength, as inferred from the values of friability testing $(0.05 \%-0.11 \%)$. There was no capping or lamination observed in any of the formulations.

\section{In vitro drug-release studies}

Drug release of about $90 \%$ at 12 hours was considered to be complete release. Figure 2 shows the drug-release profiles in comparison with the target drug-release profile. It was observed that batch AGR-4 showed the fastest drug-release profile of all batches. Drug release decreased when the concentration of carbomer was increased from $7.5 \%$ to $10 \%$ (Figure 2A). Further increases in carbomer concentration to $15 \%$ resulted in drug release much faster than $10 \%$ carbomer and closer to $7.5 \%$ carbomer. Initial swelling of the batch containing 15\% carbomer (AGR-3) was high, but the tablets split into two portions in longitudinal axis. This resulted in an increased surface area due to newly exposed surfaces and subsequently resulted in a faster drug-release profile.

Batches containing polyethylene oxide alone did not swell much and followed an erosion pattern throughout the duration of release. No residual tablets remained after completion of drug release. Drug release was inversely proportional to the concentration of polymer (Figure 2B). Polyethylene oxide had a better release-controlling effect than carbomer up to 6 hours at the same polymer concentration of $10 \%$ (AGR-2 vs AGR-5). Since the target release profile is by first-order mechanism, further investigations were not carried out on batches containing polyethylene oxide alone. Batches AGR-6, AGR-7, and AGR-8 contained a combination of carbomer and polyethylene oxide. Drug release decreased with increasing proportions of polyethylene oxide (Figure 2C). This is in accordance with the observation that polyethylene oxide controls drug release better than does carbomer. Of these three batches, the drug-release profile of AGR-6, containing 7.5\% carbomer and $2.5 \%$ polyethylene oxide, was closest to the target.

Batches containing a combination of carbomer and sodium alginate at equal concentrations split during drug release, although their drug-release profiles were closer to the target (Figure 2D). The drug-release profile of the batch containing $10 \%$ carbomer and $3.5 \%$ sodium alginate was much slower than the target.

The $f_{2}$ of drug-release profiles of all batches against the target drug-release profile as reference are summarized in Table 5 .

Table 4 In-process characterization of different batches of acyclovir gastroretentive tablets

\begin{tabular}{|c|c|c|c|c|c|}
\hline $\begin{array}{l}\text { Batch } \\
\text { number }\end{array}$ & $\begin{array}{l}\text { Average weight }(\mathrm{mg}) \\
(\mathrm{n}=20)\end{array}$ & $\begin{array}{l}\text { Weight variation (\%) } \\
(n=20)\end{array}$ & $\begin{array}{l}\text { Hardness (kp) } \\
(n=5)\end{array}$ & $\begin{array}{l}\text { Thickness }(\mathrm{mm}) \\
(\mathrm{n}=5)\end{array}$ & $\begin{array}{l}\text { Friability (\%) } \\
(n=10)\end{array}$ \\
\hline AGR-I & 996 & -1.69 to 2.26 & 17.8 to 22.7 & 6.20 to 6.34 & 0.07 \\
\hline AGR-2 & $\mathrm{I}, 002$ & -2.20 to 2.80 & 16.0 to 23.8 & 6.35 to 6.46 & 0.07 \\
\hline AGR-3 & 999 & -2.36 to 1.99 & 15.8 to 23.8 & 6.33 to 6.75 & 0.09 \\
\hline AGR-4 & 1,005 & -1.74 to 1.32 & 17.8 to 20.8 & 6.02 to 6.12 & 0.06 \\
\hline AGR-5 & $\mathrm{I}, 007$ & -1.64 to 1.37 & 19.6 to 22.6 & 5.94 to 6.03 & 0.10 \\
\hline AGR-6 & 996 & -1.52 to 2.18 & 17.7 to 21.8 & 6.14 to 6.28 & 0.07 \\
\hline AGR-7 & $\mathrm{I}, 00 \mathrm{I}$ & -1.88 to 1.85 & I 8.9 to 22.1 & 6.02 to 6.27 & 0.08 \\
\hline AGR-8 & 998 & -1.19 to 1.81 & 17.4 to 22.4 & 6.09 to 6.28 & 0.10 \\
\hline AGR-9 & $\mathrm{I}, 00 \mathrm{I}$ & -1.88 to 1.85 & I 8.9 to 22.1 & 6.02 to 6.27 & 0.05 \\
\hline AGR-I0 & 996 & -1.52 to 2.18 & 17.7 to 21.8 & 6.14 to 6.28 & 0.05 \\
\hline AGR-II & 992 & -2.80 to 2.52 & 18.1 to 21.9 & 6.16 to 6.27 & 0.11 \\
\hline
\end{tabular}

Abbreviation: AGR, acyclovir gastroretentive sustained-release. 
A

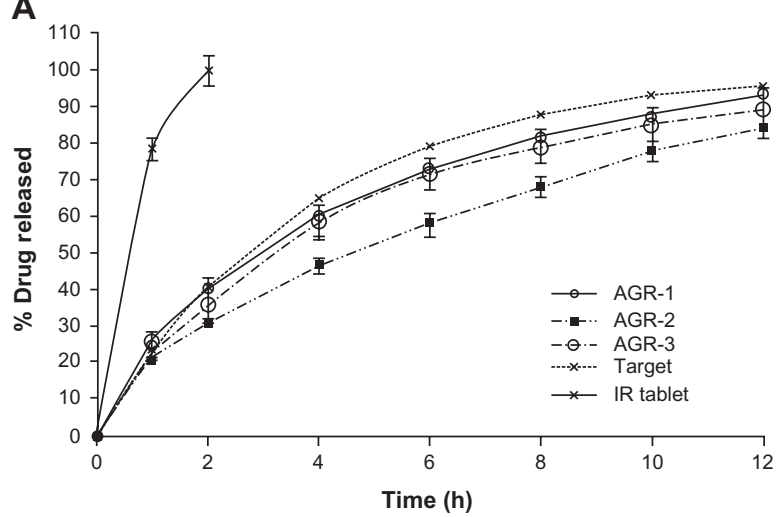

C

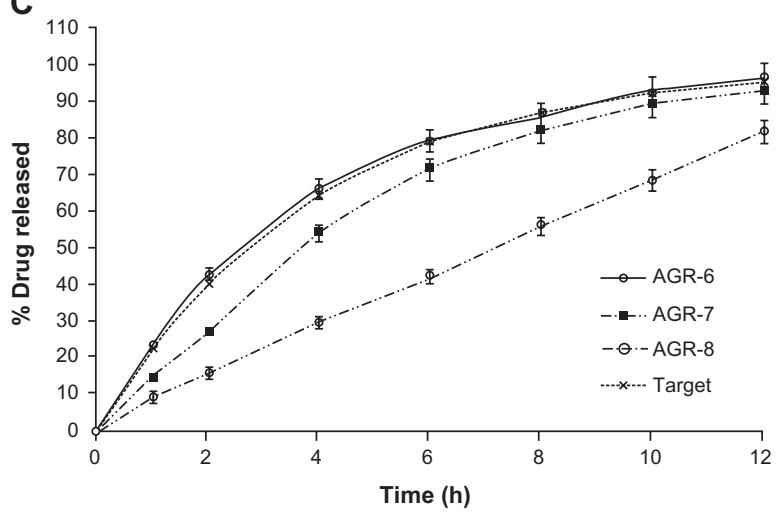

B

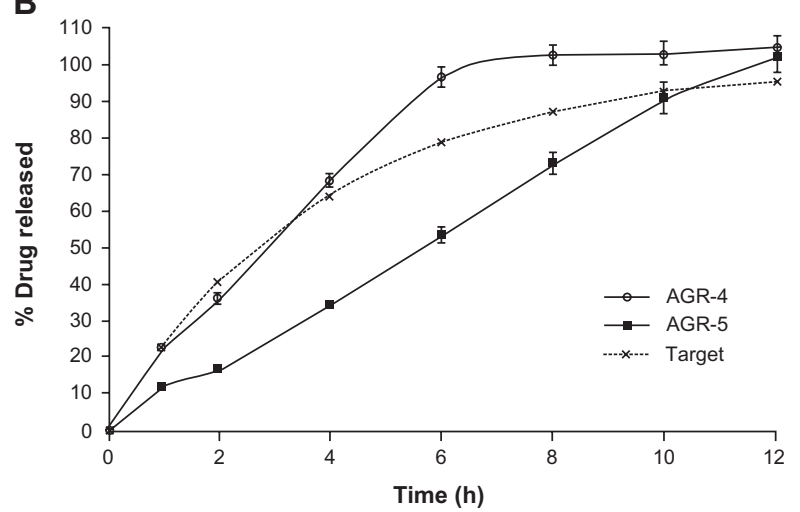

D

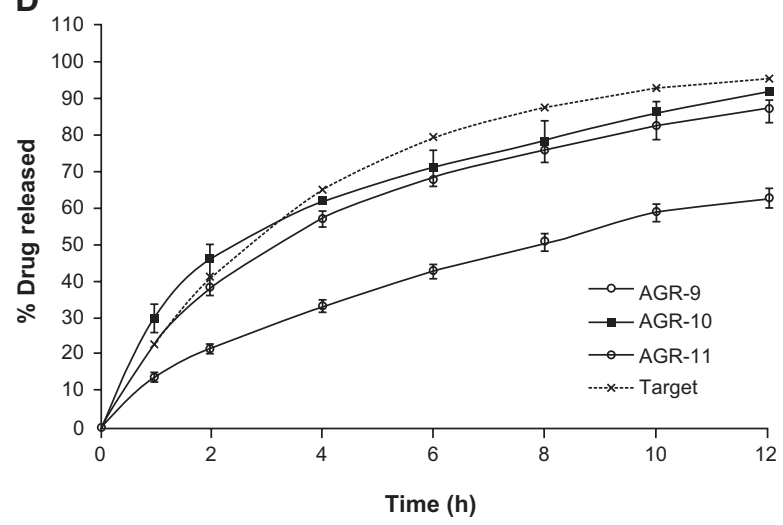

Figure 2 In vitro drug release profiles of gastroretentive tablets of acyclovir.

Note: Data are represented as mean \pm standard deviation $(n=3)$.

Abbreviations: $h$, hours; AGR, acyclovir gastroretentive sustained-release; IR, immediate-release.

Six of 11 batches had acceptable $\mathrm{f}_{2}$ values (between 50 and 100). Of the six batches with acceptable $\mathrm{f}_{2}$, AGR-3, AGR-9, and AGR-10 split during drug-release studies. In the absence of splitting, drug-release profiles of these batches must have been much slower. These three batches are not

Table 5 Similarity factor and splitting behavior of acyclovir gastroretentive tablets

\begin{tabular}{|c|c|c|c|}
\hline $\begin{array}{l}\text { Batch } \\
\text { number }\end{array}$ & $\begin{array}{l}\text { Polymer } \\
\text { composition }\end{array}$ & $\begin{array}{l}\text { Similarity } \\
\text { factor }\left(f_{2}\right)\end{array}$ & $\begin{array}{l}\text { Splitting during } \\
\text { drug release }\end{array}$ \\
\hline AGR-I & Carbomer $7.5 \%$ & 66 & No \\
\hline AGR-2 & Carbomer $10 \%$ & 41 & No \\
\hline AGR-3 & Carbomer $15 \%$ & 59 & Yes \\
\hline AGR-4 & Polyethylene oxide 5\% & 48 & No \\
\hline AGR-5 & Polyethylene oxide $10 \%$ & 35 & No \\
\hline AGR-6 & $\begin{array}{l}\text { Carbomer } 7.5 \% \text {; } \\
\text { polyethylene oxide } 2.5 \%\end{array}$ & 85 & No \\
\hline AGR-7 & $\begin{array}{l}\text { Carbomer } 5 \% \text {; } \\
\text { polyethylene oxide } 5 \%\end{array}$ & 54 & No \\
\hline AGR-8 & $\begin{array}{l}\text { Carbomer } 2.5 \% \text {; } \\
\text { polyethylene oxide } 7.5 \%\end{array}$ & 29 & No \\
\hline AGR-9 & $\begin{array}{l}\text { Carbomer } 5 \% \text {, } \\
\text { sodium alginate } 5 \%\end{array}$ & 54 & Yes \\
\hline AGR-10 & $\begin{array}{l}\text { Carbomer } 3.5 \% \text {; } \\
\text { sodium alginate } 3.5 \%\end{array}$ & 58 & Yes \\
\hline AGR-II & $\begin{array}{l}\text { Carbomer } 10 \% ; \\
\text { sodium alginate } 3.5 \%\end{array}$ & 26 & No \\
\hline
\end{tabular}

Abbreviation: AGR, acyclovir gastroretentive sustained-release. suitable for gastroretention due to the smaller size of split portions compared with the whole tablet.

AGR-1, AGR-6, and AGR-7 had acceptable $f_{2}$ values without splitting of tablets during drug-release testing. Since AGR-6 had the highest $f_{2}$ value among the three batches, it was considered the most optimal formulation. Apart from AGR-6, both AGR-7 and AGR-8 were also taken up for further in vitro characterization, since the formulation strategy of these two batches was similar to that of AGR-6 (combination of carbomer and polyethylene oxide).

The drug-release data were fitted to zero-order, first-order, Higuchi, Korsmeyer-Peppas, and Hixson-Crowell equations to ascertain the kinetic modeling of drug release. The release rate kinetic data of batches containing a combination of carbomer and polyethylene oxide are shown in Table 6. In terms of $\mathrm{R}^{2}$ value, AGR- 6 and AGR-7 had the best fit with the first-order release model, whereas AGR-8 fitted well with the zero-order release model. The drug transport mechanism of all three batches was found to be anomalous (non-Fickian) diffusion as determined by an $\mathrm{n}$ value $>0.45$ and $<0.89$. As the quantity of polyethylene oxide increased, the $n$ value increased towards case II transport, that is, towards 
Table 6 Mathematical modeling and drug-release kinetics of acyclovir gastroretentive formulations

\begin{tabular}{|c|c|c|c|c|c|c|c|c|}
\hline \multirow{2}{*}{$\begin{array}{l}\text { Batch } \\
\text { number }\end{array}$} & \multirow{2}{*}{$\begin{array}{l}\text { Carbomer: } \\
\text { polyethylene oxide }\end{array}$} & \multicolumn{5}{|l|}{$\mathbf{R}^{2}$} & \multirow[t]{2}{*}{$\mathbf{n}$} & \multirow{2}{*}{$\begin{array}{l}\text { Drug-transport } \\
\text { mechanism }\end{array}$} \\
\hline & & $\begin{array}{l}\text { Zero } \\
\text { order }\end{array}$ & $\begin{array}{l}\text { First } \\
\text { order }\end{array}$ & Higuchi & $\begin{array}{l}\text { Korsmeyer- } \\
\text { Peppas }\end{array}$ & $\begin{array}{l}\text { Hixson- } \\
\text { Crowell }\end{array}$ & & \\
\hline AGR-6 & $75: 25$ & 0.8846 & 0.9911 & 0.9624 & 0.9648 & 0.9897 & 0.55 & Anomalous \\
\hline AGR-7 & $50: 50$ & 0.9189 & 0.9988 & 0.9786 & 0.9768 & 0.9915 & 0.75 & transport \\
\hline AGR-8 & $25: 75$ & 0.9999 & 0.9518 & 0.9784 & 0.9987 & 0.9797 & 0.87 & (non-Fickian) \\
\hline
\end{tabular}

Abbreviation: AGR, acyclovir gastroretentive sustained-release.

erosion-controlled zero-order release. Visual observation of drug-release profiles of these batches also concur with this observation (Figure 2C).

\section{Swelling index and matrix erosion}

Figure 3 shows the swelling profiles of the acyclovir GR formulation. The swelling of all three batches was initially very rapid and then declined slowly in a sustained manner. The maximum swelling index obtained was $255.7 \%$ ( 0.75 hours), $163.5 \%$ ( 0.75 hours), and $145.3 \%$ ( 0.5 hours) for AGR-6, AGR-7, and AGR-8, respectively. The swelling index decreased with increasing proportions of polyethylene oxide. The swelling profile of all the batches also followed a similar trend. This behavior is similar to the drug-release profile. Swelling is an important characteristic of polymer that controls the drug release and increases the gastrointestinal retention of GR tablets. Swelling is also an important parameter for the mucoadhesion property of the formulation. ${ }^{44}$ A number of studies showed the direct relationship between swelling and mucoadhesion. ${ }^{45,46}$ To develop maximum adhesion strength, an optimum concentration is needed for polymers to form a cohesive bond.

Figure 4 shows the results of the matrix erosion study. The results of matrix erosion are in accordance with the swelling index. Erosion was greater when the proportion of polyethylene oxide was higher. Erosion of AGR-6 and AGR-7 was much slower than the drug release, but was faster in AGR-8. This indicates that the drug release is more erosion-controlled as the proportion of polyethylene oxide increases. This is in agreement with the results of drug-release kinetics.

Rapid swelling and controlled erosion of the GR tablet are essential for better gastroretention. To avoid gastric empty-

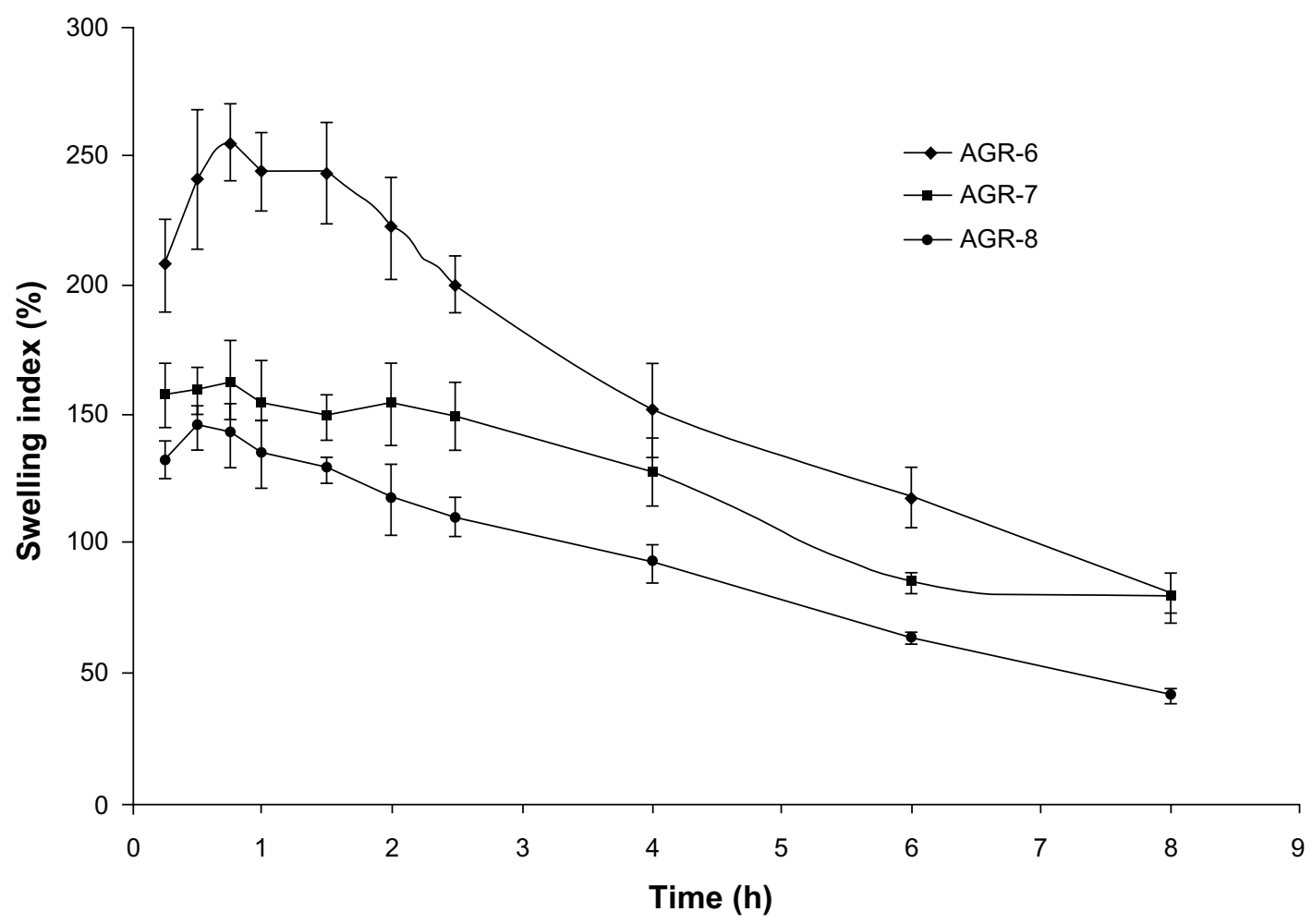

Figure 3 Swelling index of gastroretentive tablets of acyclovir.

Note: Data are represented as mean \pm standard deviation $(n=3)$.

Abbreviations: h, hours; AGR, acyclovir gastroretentive sustained-release. 


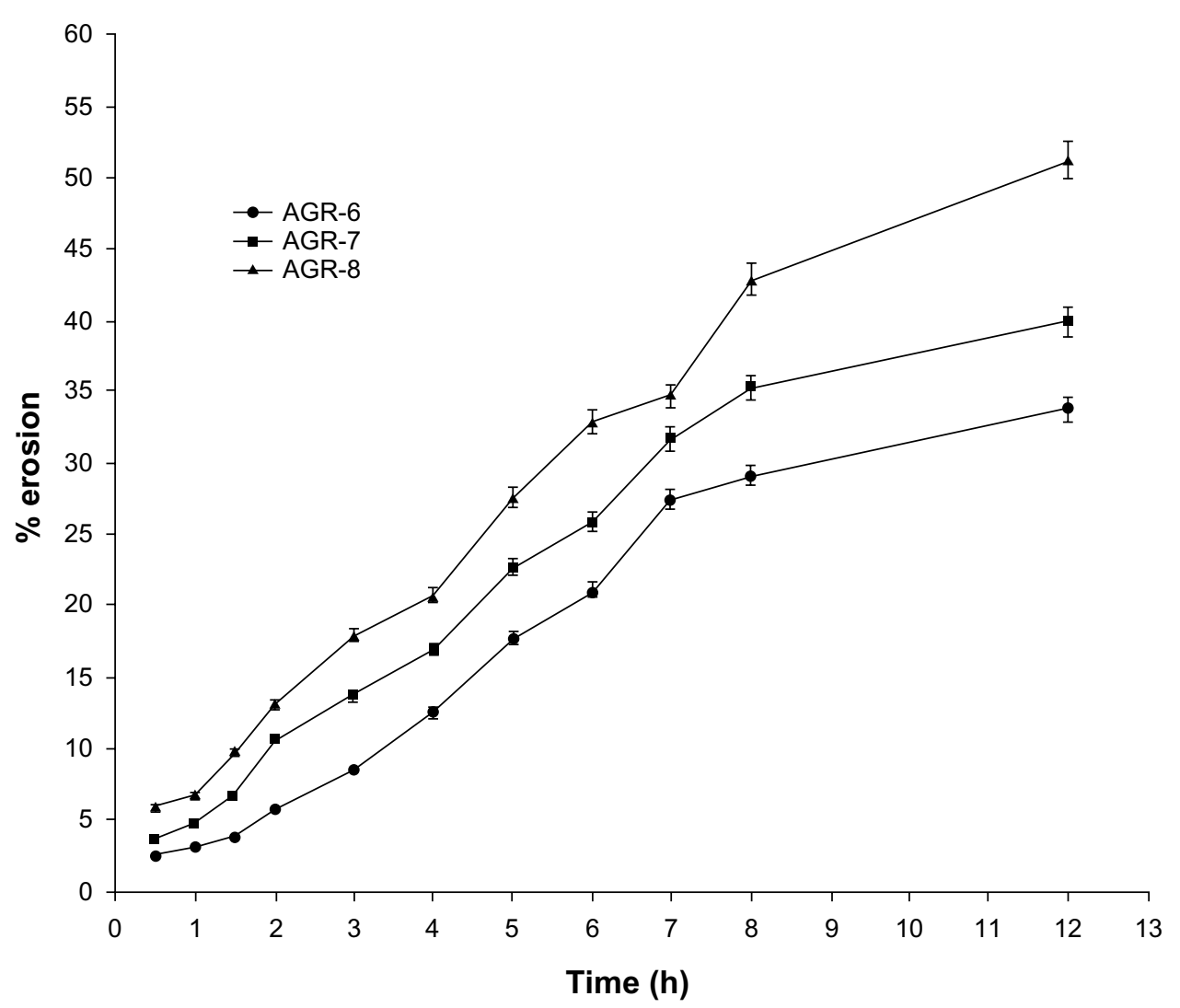

Figure 4 Matrix erosion of gastroretentive tablets of acyclovir.

Note: Data are represented as mean \pm standard deviation $(n=3)$.

Abbreviations: h, hours; AGR, acyclovir gastroretentive sustained-release.

ing, the dosage form should be larger than about $13 \mathrm{~mm} .{ }^{47}$ Figure 5 shows the relative size of the optimized acyclovir GR tablet after 8 hours of dissolution. Results showed that the optimized GR tablet maintained a size $>13 \mathrm{~mm}$ up to 8 hours.

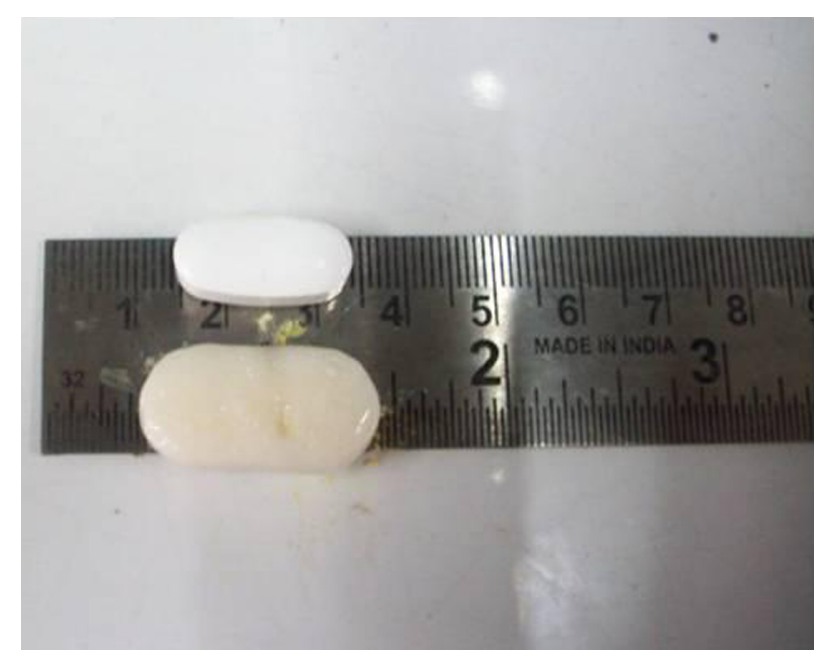

Figure 5 Relative size of optimized GR formulation. Abbreviation: GR, gastroretentive sustained-release.

\section{Mucoadhesive strength}

Mucoadhesive strength (measured in terms of detachment force using a texture analyzer) of the most optimal formulation (AGR-6) was much higher than the marketed IR formulation, Zovirax ${ }^{\circledR}(19.3 \mathrm{~g} \pm 4.7 \mathrm{~g}$ vs $9.3 \mathrm{~g} \pm 0.8 \mathrm{~g})$ and was the highest of all three batches tested (Figure 6). Detachment force decreased with increasing concentrations of polyethylene oxide.

Although polyethylene oxide is highly hydrophilic and has a high degree of functional groups with hydrogenbonding ability, AGR-8, containing a major proportion of polyethylene oxide, showed the lowest detachment force. It was similar to that of Zovirax $^{\circledR}$, which is a conventional dosage form. This could be because AGR- 8 has the lowest water uptake of the three batches. Sufficient hydration of the polymer network is necessary for the complete opening of the inter-polymeric pores within the polymer matrix in addition to the mobilization of the polymer chains. ${ }^{48}$

\section{Gastroretention study}

An in vivo radiographic study was conducted on healthy albino rabbits to determine the gastric retention time of the 


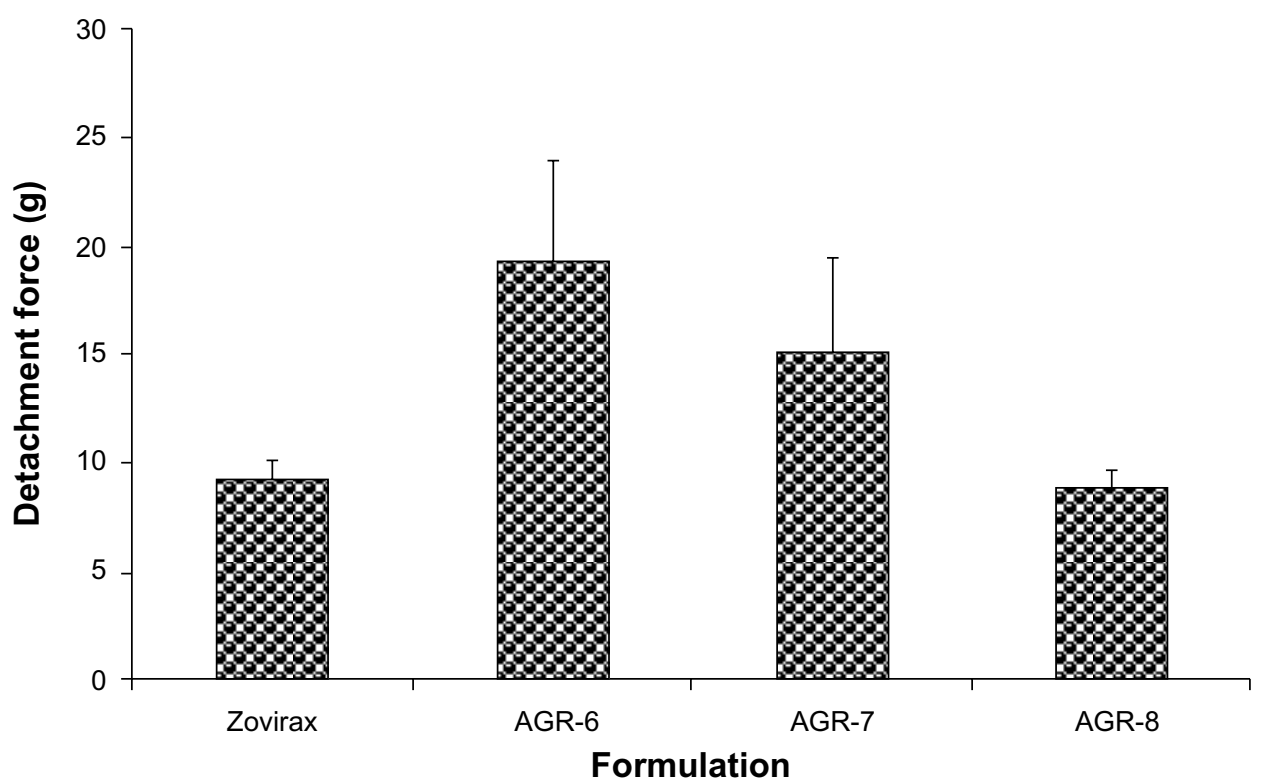

Figure 6 Detachment forces of different batches of gastroretentive and conventional acyclovir tablets in mucoadhesion study. Note: Data are represented as mean \pm standard deviation $(n=3)$.

tablet. For this study, a GR tablet of $6.0 \mathrm{~mm}$ diameter and $110 \mathrm{mg}$ weight was prepared for optimized batch AGR-6 (containing a combination of carbomer and polyethylene oxide in the ratio of 75:25). Batch AGR-6 was selected as the optimized batch due to its high bioadhesive strength and swelling index and acceptable drug-release characteristics. Images were taken at different time points to find the location
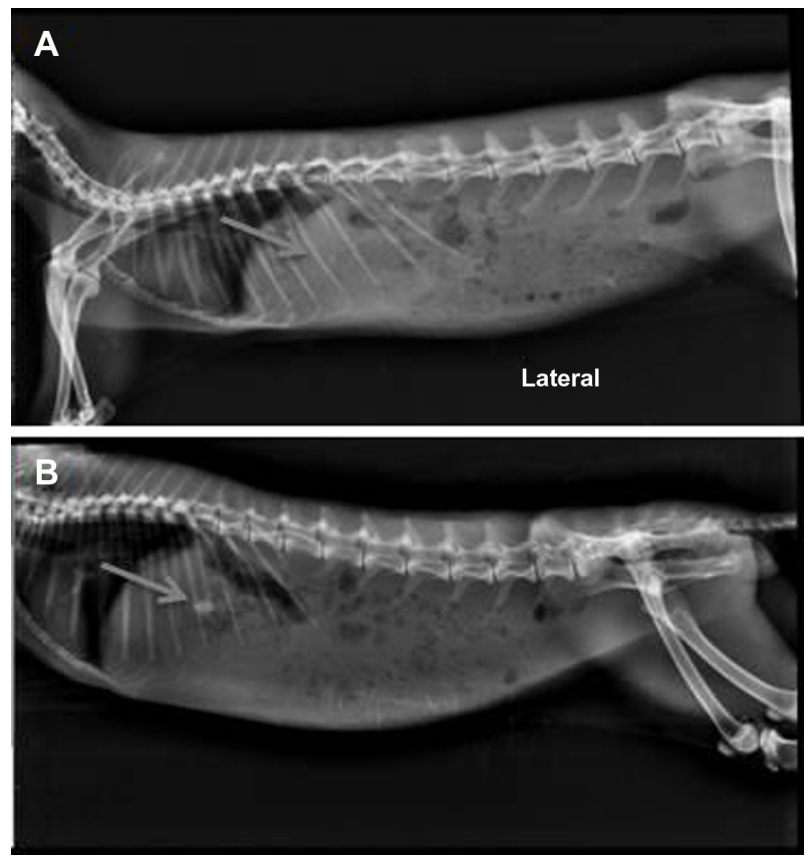

Figure 7 X-ray radiography photographs of rabbit administered with IR tablet at 2 hours (A) and 8 hours (B) with optimized GR formulation (AGR-6).

Abbreviations: IR, immediate-release; GR, gastroretentive sustained-release; AGR, acyclovir gastroretentive sustained-release. of the tablet; gastric residence time was calculated based on this. The gastric residence time of the GR formulation was found to be 480 minutes in comparison with 90 minutes for the conventional IR tablet (Figure 7). From this study, it is clear that the conventional IR tablet was quickly emptied from stomach, but the retention of the GR formulation was prolonged, up to 8 hours. The increased gastric retention time of the GR formulation is due to the synergistic mechanism of swelling and bioadhesion. These results are in accordance with the in vitro studies.

\section{Pharmacokinetic study}

Table 7 shows the comparative pharmacokinetic parameters of the optimized GR formulation (AGR-6, containing a

Table 7 Pharmacokinetic parameters of acyclovir after administration of GR and IR formulations

\begin{tabular}{lccl}
\hline Parameter & $\begin{array}{l}\text { GR formulation } \\
\text { (AGR-6) }\end{array}$ & IR formulation & $\begin{array}{l}\text { Ratio of GR } \\
\text { to IR (\%) }\end{array}$ \\
\hline $\mathrm{t}_{\text {max }}($ hours $)$ & $4 \pm 0.1$ & $1.5 \pm 0.2$ & 267 \\
$\mathrm{C}_{\text {max }}(\mathrm{ng} / \mathrm{mL})$ & $292.6 \pm 7.5$ & $295.4 \pm 5.9$ & 99 \\
$\mathrm{AUC}_{\mathrm{t}}$ & $3,100.7 \pm 94.8$ & $\mathrm{I}, 152.9 \pm 48.1$ & 269 \\
$(\mathrm{ng} \times \mathrm{h} / \mathrm{mL})$ & & & \\
$\mathrm{AUC}$ & & & \\
$(\mathrm{ng} \times \mathrm{h} / \mathrm{mL})$ & $3,526.1 \pm 107.3$ & $\mathrm{I}, 350.2 \pm 69.8$ & $26 \mathrm{I}$ \\
$\mathrm{MRT}($ hours $)$ & $7.0 \pm 0.3$ & $3.3 \pm 0.2$ & 212 \\
\hline
\end{tabular}

Note: Data represented as mean $\pm S D(n=3)$.

Abbreviations: $A G R$, acyclovir gastroretentive sustained-release; $A \cup C_{\text {inf }}$ area under the concentration-time curve from time 0 to infinity; $A \cup C_{t}$, area under the concentration-time curve from 0 to $t$; $C_{\max }$, peak plasma concentration; $G R$, gastroretentive sustained-release; IR, intermediate-release; MRT, mean residence time; $S D$, standard deviation; $t_{\max }$, time to $C_{\max }$; $G R$, gastroretentive sustained-release. 


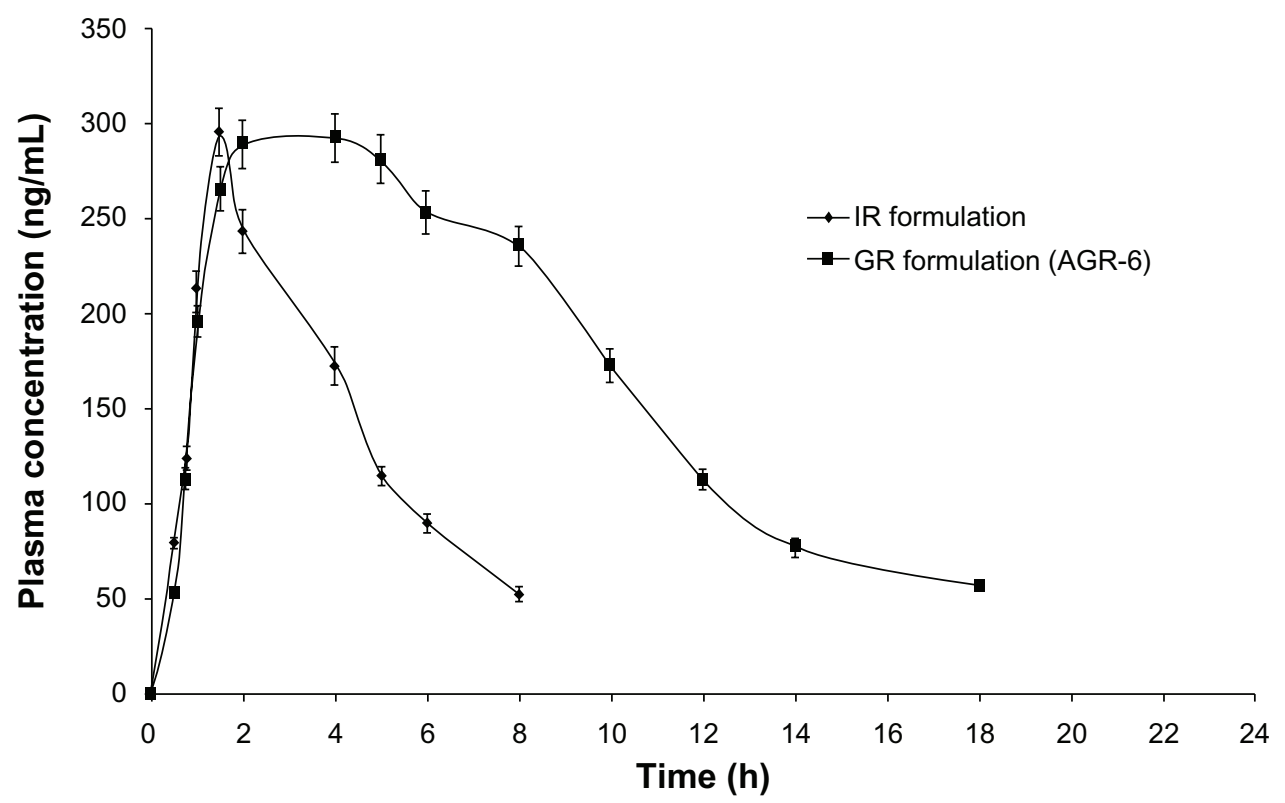

Figure 8 Mean plasma concentration profiles of IR and optimized GR formulation (AGR-6)

Note: Data are represented as mean \pm standard deviation $(n=3)$.

Abbreviations: IR, immediate-release; GR, gastroretentive sustained-release; AGR, acyclovir gastroretentive sustained-release; $h$, hours.

combination of carbomer and polyethylene oxide in the ratio of 75:25) and the IR formulation. The GR formulation had a similar maximum plasma drug concentration $\left(\mathrm{C}_{\max }\right)$ and longer time to $\mathrm{C}_{\max }\left(\mathrm{t}_{\max }\right)$ compared with the IR formulation. The bioavailability of the GR formulation was significantly higher (2.6-fold) than that of the IR formulation. The plasma-concentration profile of the GR formulation indicated sustained absorption compared with the IR formulation (Figure 8). The results are in strong agreement with those of the gastroretention study. Poor oral bioavailability (15\%$30 \%$ ) of acyclovir from conventional formulations is due to its narrow absorption window in the upper parts of the GIT. As the gastric residence time of the GR formulation is prolonged, small amounts of the drug are continuously released in the absorbable regions of the GIT, thereby increasing its bioavailability. Since the $\mathrm{C}_{\text {max }}$ of the GR formulation is similar to that of the IR formulation, similar anti-viral activity can be expected. At the same time, prolonged absorption of the

Table 8 Stability data of optimized batch of acyclovir gastroretentive sustained-release formulation (AGR-6)

\begin{tabular}{lllll}
\hline Parameter & Initial & $\begin{array}{l}\text { After } \\
\text { I month }\end{array}$ & $\begin{array}{l}\text { After } \\
\text { 2 months }\end{array}$ & $\begin{array}{l}\text { After 3 } \\
\text { months }\end{array}$ \\
\hline Assay $(\%)$ & 99.8 & 100.2 & 99.9 & 99.7 \\
Guanine content $(\% \mathrm{w} / \mathrm{w})$ & 0.32 & 0.40 & 0.39 & 0.40 \\
Water content $(\% \mathrm{w} / \mathrm{w})$ & 5.7 & 5.9 & 5.8 & 5.8 \\
Drug-release similarity & - & 87 & 84.8 & 91.4 \\
factor $\left(\mathrm{f}_{2}\right)$ & & & & \\
\hline
\end{tabular}

Abbreviation: AGR, acyclovir gastroretentive sustained-release.
GR formulation will help in reducing the dosing frequency of the currently marketed IR formulation.

\section{Stability study}

Table 8 shows the assay, water content, guanine content, and drug release of a batch with the same composition as the optimized batch, AGR-6, under accelerated stability-test conditions at 1,2, and 3 months. There was no significant change in assay, water content, or guanine content. The drug-release profile was similar to the initial profile. It can be inferred from the data that the formulation is stable up to 3 months. The stability study is being continued up to 6 months.

\section{Conclusion}

A GR formulation of acyclovir has been developed with an in vitro drug-release profile similar to that of the target profile obtained through pharmacokinetic simulations. The formulation has been found to have a high degree of swelling and mucoadhesion properties. The gastric residence time of the optimized GR formulation was much higher than that of the IR formulation. The optimized GR formulation also had prolonged absorption and 2.6-fold higher bioavailability than the conventional formulation. An in vivo pharmacokinetic study showed a constant maintenance of plasma concentration for a prolonged period of time, essential for chronic treatment of viral disease. The results demonstrated that the developed GR formulation will increase the anti-viral activity of acyclovir and improve patient compliance by reducing the dosing frequency of 
conventional formulations. The GR formulation might represent a better alternative for sustained and efficacious delivery of acyclovir.

\section{Acknowledgment}

The authors are grateful to BioPlus Life Sciences Pvt Ltd, India, for providing financial assistance.

\section{Disclosure}

The authors report no conflicts of interest in this work.

\section{References}

1. Hoffman A. Pharmacodynamic aspects of sustained release preparations. Adv Drug Deliv Rev. 1998;33:185-199.

2. Klausner EA, Lavy E, Friedman M, Hoffman A. Expandable gastroretentive dosage forms. J Control Release. 2003;90:143-162.

3. Qassim SMA, inventor; Tabuk Pharmaceutical Manufacturing Co, assignee. Pharmaceutical compositions of ciprofloxacin. European patent EP1880722B1. March 17, 2010.

4. Hoffman A, Stepensky D. Pharmacodynamic aspects of modes of drug administration for optimization of drug therapy. Crit Rev Ther Drug Carrier Syst. 1999;16:571-639.

5. Dhaliwal S, Jain S, Singh HP, Tiwary AK. Mucoadhesive microspheres for gastroretentive delivery of acyclovir: in vitro and in vivo evaluation. AAPS J. 2008;10:322-330.

6. Riner JL, Byford RL, Stratton LG, Hair JA. Influence of density and location on degradation of sustained-release boluses given to cattle. Am J Vet Res. 1982;43(11):2028-2030.

7. Reddy LH, Murthy RS. Floating dosage systems in drug delivery. Crit Rev Ther Drug Carrier Syst. 2002;19(6):553-585.

8. Klausner EA, Eyal S, Lavy E, Friedman M, Hoffman A. Novel levodopa gastroretentive dosage form: in vivo evaluation in dogs. J Control Release. 2003;88(1):117-126.

9. Kedzierewicz F, Thouvenot P, Lemut J, Etienne A, Hoffman M, Maincent P. Evaluation of peroral silicone dosage forms in humans by gamma-scintigraphy. J Control Release. 1999;58(2):195-205.

10. Chen J, Blevins WE, Park H, Park K. Gastric retention properties of superporous hydrogel composites. J Control Release. 2000;64(1-3): 39-51.

11. Akiyama Y, Nagahara N, Nara E, et al. Evaluation of oral mucoadhesive microspheres in man on the basis of the pharmacokinetics of furosemide and riboflavin, compounds with limited gastrointestinal absorption sites. J Pharm Pharmacol. 1998;50(2):159-166.

12. Groning R, Berntgen M. Estimation of the gastric residence time of magnetic dosage forms using the Heidelberg capsule. Pharmazie. 1996;51(5):328-331.

13. Chiou WL, Barve A. Linear correlation of the fraction of oral dose absorbed of 64 drugs between humans and rats. Pharm Res. 1998;15(11):1792-1795.

14. Lewis LD, Fowle ASE, Bittiner SB, Bye A, Isaacs PET. Human gastrointestinal absorption of acyclovir from tablet duodenal infusion and sipped solution. Br J Clin Pharmacol. 1986;21(4): 459-462.

15. Gröning R, Berntgen M, Georgarakis M. Acyclovir serum concentrations following peroral administration of magnetic depot tablets and the influence of extracorporal magnets to control gastrointestinal transit. Eur J Pharm Biopharm. 1998;46(3):285-291.

16. O'Brien JJ, Campoli-Richards DM. Acyclovir: an updated review of its antiviral activity, pharmacokinetic properties and therapeutic efficacy. Drugs. 1989;37(3):233-309.

17. Fuertes I, Miranda A, Millán M, Caraballo I. Estimation of the percolation thersholds in acyclovir hydrophilic matrix tablets. Eur J Pharm Biopharm. 2006;64(3):336-342.
18. Garg R, Gupta GD. Preparation and evaluation of gastroretentive floating tablets of acyclovir. Curr Drug Deliv. 2009;6(5):437-443.

19. Sankar R, Jain SK. Determination of target in vitro drug release profile for extended release formulation of acyclovir through pharmacokinetic simulations. Anti-Infect Agents. 2013;11(2):204-211.

20. United States Pharmacopeia and National Formulary (USP 36-NF 31). Acyclovir tablets. Rockville, MD: The United States Pharmacopeial Convention; 2013:2342-2343.

21. Indian Pharmacopoeia. Uniformity of weight of single dose preparations. Ghaziabad: Indian Pharmacopoeia Commission; 2010;1:192.

22. Indian Pharmacopoeia. Friability of uncoated tablets. Ghaziabad: Indian Pharmacopoeia Commission; 2010;1:193.

23. Moore JW, Flanner HH. Mathematical comparison of dissolution profiles. Pharm Tech. 1996;20:64-74.

24. Costa P, Lobo JMS. Modeling and comparison of dissolution profiles. Eur J Pharm Sci. 2001;13(2):123-133.

25. Siepmann J, Peppas NA. Modeling of drug release from delivery systems based on hydroxypropyl methylcellulose (HPMC). Adv Drug Deliv Rev. 2001;48(2-3):139-157.

26. Al-Taani BM, Tashtoush BM. Effect of microenvironment $\mathrm{pH}$ of swellable and erodable buffered matrices on the release characteristics of diclofenac sodium. AAPS PharmSciTech. 2003; 4(3):E43.

27. Ravindran VK, Vasa S, Subadhra S, Banji D, Banji O, Rao YM. Comparative study of mucoadhesive polymers carbopol $974 \mathrm{P}$ and sodium carboxymethyl cellulose for single unit dosage of imatinib mesylate. Malaysian J Pharm Sci. 2012;10(1):61-77.

28. Badhan AC, Mashru RC, Shah PP, Thakkar AR, Dobaria NB. Development and evaluation of sustained release gastroretentive minimatrices for effective treatment of $\mathrm{H}$. pylori infection. AAPS PharmSciTech. 2009;10(2):459-467.

29. Baskar GV, Narayanan N, Gaikwad R, Abdul S. Formulation and evaluation of gastro-retentive floating multi-particulate system of metoprolol tartarate. Trop J Pharm Res. 2010;9(2):181-186.

30. Nagarwal RC, Ridhurkar DN, Pandit JK. In vitro release kinetics and bioavailability of gastroretentive cinnarizine hydrochloride tablet. AAPS PharmSciTech. 2010;11(1):294-303.

31. Thakar K, Joshi G, Sawant KK. Bioavailability enhancement of baclofen by gastroretentive floating formulation: statistical optimization, in vitro and in vivo pharmacokinetic studies. Drug Dev Ind Pharm. 2013;39(6):880-888.

32. Chary RBR, Vani G, Rao YM. In vitro and in vivo adhesion testing of mucoadhesive testing of mucoadhesive drug delivery systems. Drug Dev Ind Pharm. 1999;25(5):685-690.

33. United States Pharmacopeia and National Formulary (USP 36-NF 31). Acyclovir. Rockville, MD: The United States Pharmacopeial Convention; 2013:2338-2339.

34. International Conference on Harmonisation of Technical Requirements for Registration of Pharmaceuticals for Human Use [webpage on the Internet]. ICH Q1C. Stability testing for new dosage forms. 1997. Available from: http://www.ich.org/products/guidelines/quality/article/ quality-guidelines.html. Accessed January 15, 2013.

35. Colorcon. Polyox ${ }^{T M}$, Water-Soluble Polymers for Pharmaceutical Applications. Harleysville (PA): BPSI Holdings, LLC; 2009. Available from: http://www.colorcon.com/literature/marketing/mr/Extended $\% 20$ Release/POLYOX/English/Colorcon_PIB_POLYOX.pdf. Accessed April 12, 2013.

36. Lubrizol. Pharmaceutical Polymers for Oral Solid Dosage Forms. Cleveland $(\mathrm{OH})$ : Lubrizol; 2011. Available from: http://www.lubrizol.com/ Pharmaceutical-Ingredients/Documents/Brochures/PharmaceuticalPolymers-for-Oral-Solid-Dosage-Forms.pdf. Accessed April 12, 2013.

37. FMC Corporation. Alginates for Pharmaceutical and Medical Applications: Performance Enhancing Products. Philadelphia (PA): FMC Corporation; 2008. Available from: http://www.fmcbiopolymer.com/Portals/ISP/Content/Docs/Alginates $\% 20$ for $\% 20$ Pharmaceutical\%20and\%20Medical\%20Applications.pdf. Accessed April 12, 2013. 
38. Chen JL, Cyr GN. Compositions producing adhesion through hydration. In: Manly RS, editor. Adhesion in Biological Systems. New York: Academic Press; 1970:163-181.

39. Duchêne D, Ponchel G. Principle and investigation of the bioadhesion mechanism of solid dosage forms. Biomaterials. 1992;13(10): 709-715.

40. Park H, Robinson JR. Physico-chemical properties of water insoluble polymers important to mucin/epithelial adhesion. J Control Release. 1985;2:47-57.

41. Shahi S, Sonawane A, Vanamore S, Zadbuke N. Formulation and in vitro characterization of acyclovir floating matrix tablets: a factorial design study. J Applied Pharm Sci. 2013;3(5):65-74.

42. Wells JI, Aulton ME. Preformulation. In: Aulton ME, editor. Pharmaceutics: The Science of Dosage Form Design. London: Churchill Livingstone; 1988:247-248.

43. International Conference on Harmonisation of Technical Requirements for Registration of Pharmaceuticals for Human Use [webpage on the Internet]. ICH Q3C(R5). Impurities: guideline for residual solvents; 2011. Available from: http://www.ich.org/products/guidelines/quality/ article/quality-guidelines.html. Accessed April 12, 2013.
44. Gu JM, Robinson JR, Leung SH. Binding of acrylic polymers to mucin/ epithelial surfaces: structure-property relationships. Crit Rev Ther Drug Carrier Syst. 1988;5(1):21-67.

45. Shaikh R, Raj Singh TR, Garland MJ, Woolfson AD, Donnelly RF. Mucoadhesive drug delivery systems. J Pharm Bioallied Sci. 2011;3(1):89-100.

46. Roldo M, Hornof M, Coliceti P, Bernkop-Schnürch A. Mucoadhesive thiolated chitosans as platforms for oral controlled drug delivery: synthesis and in vitro evaluation. Eur J Pharm Biopharm. 2004;57(1): 115-121.

47. Streubel A, Siepmann J, Bodmeier R. Drug delivery to the upper small intestine window using gastroretentive technologies. Curr Opin Pharmacol. 2006;6(5):501-508.

48. Middleton DL, Leung SS, Robinson JR. Ocular bioadhesive delivery systems. In: Lenaerts V, Gurny R, editors. Bioadhesive Drug Delivery Systems. Boca Raton (FL): CRC Press, Inc; 1990:179-202.

\section{Publish your work in this journal}

Drug Design, Development and Therapy is an international, peerreviewed open-access journal that spans the spectrum of drug design and development through to clinical applications. Clinical outcomes, patient safety, and programs for the development and effective, safe, and sustained use of medicines are a feature of the journal, which has also been accepted for indexing on PubMed Central. The manuscript management system is completely online and includes a very quick and fair peer-review system, which is all easy to use. Visit http://www.dovepress.com/testimonials.php to read real quotes from published authors.

Submit your manuscript here: http://www.dovepress.com/drug-design-development-and-therapy-journal 